\title{
EXPERIENTIAL MARKETING DAN BRANDED CUSTOMER EXPERIENCE KAITANNYA DENGAN LOYALITAS PELANGGAN RESTORAN DAN CAFE SERTA DAMPAKNYA PADA CITRA BANDUNG SEBAGAI DESTINASI PARIWISATA INDONESIA
}

\author{
Lili Adi Wibowo
}

\begin{abstract}
Abstrak
Meningkatnya intensitas persaingan bisnis restoran dan café menyebabkan penurunan tingkat loyalitas pelanggan. Situasi ini mengakibatkan terancamnya eksistensi bisnis restoran dan café, sehingga perlu dilakukan revitalisasi dalam rangka menciptakan dan mempertahankan loyalitas pelanggan melalui strategi penciptaan program experiential marketing yang tepat, unik dan berkesinambungan dalam rangka membangun branded customer experience. Dengan eksisnya bisnis restoran dan cafe diharapkan dapat menciptakan citra Bandung sebagai kota restoran dan cafe yang unik yang akhirnya dapat memberikan daya tarik sebagai destinasi pariwisata Indonesia. Penelitian ini bertujuan untuk menganalisis pengaruh experiential marketing terhadap branded customer experience dan loyalitas pelanggan restoran dan café, serta dampaknya pada citra Bandung sebagai destinasi pariwisata Indonesia. Metode penelitian yang digunakan yaitu metode descriptive dan explanatory survey dengan ukuran sampel sebanyak 440 pelanggan dari 14 restoran dan cafe di Bandung melalui wawancara, observasi, angket, serta dokumentasi. Teknik analisis data adalah Structural Equation Model dengan program Lisrel. Hasil penelitian menunjukkan bahwa experiential marketing dan branded customer experience secara bersama-sama berpengaruh lebih besar terhadap loyalitas pelanggan restoran dan cafe maupun terhadap citra Bandung dibandingkan pengaruh langsung dari masing-masing variabel tersebut. Temuan empirik yang menarik bahwa faktor pembentuk experiential marketing adalah variasi dan kualitas makanan, atmosfir, kecepatan pelayanan, nilai, kenyamanan dan layout restoran dan cafe. Citra Bandung yang melekat di benak pelanggan restoran dan cafe adalah sebagai pusat belanja factory outlet. Temuan teoritik menunjukkan perlu adanya reklasifikasi atas premis Mona A. Clark dan Roy C. Wood, Lewis, After Auty, June dan Smith bahwa loyalitas pelanggan tidak semata dipengaruhi faktor kualitas makanan dan harga namun juga faktor atmosfir.

Kata Kunci: Experiential Marketing (EXEM), Branded Customer Experience (BCE), Loyalitas Pelanggan. dan Citra Bandung
\end{abstract}

\section{PENDAHULUAN}

Pemerintah Indonesia telah sejak lama menjadikan pariwisata sebagai sumber penting pendapatan devisa negara. Biro Pusat Statistik (BPS) mencatat bahwa pariwisata Indonesia saat ini merupakan sektor terbesar kedua setelah minyak-gas (migas), yang menghasilkan penerimaan devisa mencapai sekitar 4,5 milliar USD dengan kunjungan sebesar 5.321 juta wisatawan mancanegara (wisman). Oleh karena itu, pemerintah memproyeksikan sektor pariwisata sampai dengan tahun 2009 yang secara lengkap disajikan dalam Tabel 1 berikut.
Tabel 1

Proyeksi Sasaran Pariwisata Indonesia

\begin{tabular}{|l|l|l|l|}
\hline TARGET & $\mathbf{2 0 0 7}$ & $\mathbf{2 0 0 8}$ & $\mathbf{2 0 0 9}$ \\
\hline Target Wisatawan Mancanegara & 8 juta & 9 juta & 10 juta \\
\hline Penerimaan Devisa & U\$ 8 M & U\$ 9 M & U\$ 10 M \\
\hline Target Wisatawan Nusantara & $\begin{array}{l}152 \\
\text { juta }\end{array}$ & $177 j u t a$ & 200 juta \\
\hline Peredaran Uang & $\begin{array}{l}\text { Rp } 120 \\
\text { T }\end{array}$ & Rp 135 T & Rp 150 T \\
\hline Multiplier Efek & $\begin{array}{l}\text { Rp } 300 \\
\text { T }\end{array}$ & Rp 325 T & Rp 350 T \\
\hline Lapangan Kerja Langsung & 11 juta & 11,5 juta & 12 juta \\
\hline Lapangan Kerja Tidak Langsung & $\begin{array}{l}40 \text { juta } \\
\text { 45 juta }\end{array}$ & 50 juta \\
\hline Budget & $\begin{array}{l}\text { U\$75 } \\
\text { juta }\end{array}$ & U\$ 85 juta & $\begin{array}{l}\text { U\$100 } \\
\text { juta }\end{array}$ \\
\hline
\end{tabular}

Sumber: PHRI tahun 2005 (dalam Makalah Seminar Indonesia Ultimate in Diversity) 
Walaupun pariwisata dipandang penting sebagai penyumbang terbesar kedua devisa negara, tetapi dilihat dari perjalanannya dalam empat dekade terakhir ini, nilai penting bidang pariwisata tidak diikuti oleh pengelolaan yang baik, khususnya terhadap manajemen maupun objek pariwisata itu sendiri. Kondisi tersebut, diperburuk lagi dengan serangkaian musibah yang terjadi di dalam negeri, seperti ganguan faktor keamanan, bencana alam, kecelakaan angkutan udara, laut dan darat, wabah flu burung serta deman berdarah, serta situasi lainnya menambah "derita" pariwisata Indonesia. Dampak dari permasalahan pariwisata tersebut, mengakibatkan menurunnya jumlah kunjungan wisman ke Indonesia. Pada tahun 2004, terdapat sekitar 5.3 juta wisman datang ke Indonesia, turun menjadi 5 juta wisman pada tahun 2005 dan semakin turun sebanyak 2,61 persen di banding tahun 2005 dari tahun 2006 yaitu menjadi 4.87 juta orang.

Upaya pemerintah meningkatkan citra pariwisatanya dalam mewujudkan "Indonesia The Ultimate Diversity", mengalami kendala dalam hal promosi. Minimnya dana promosi pariwisata Indonesia mengakibatkan orang asing tidak begitu mengenal Indonesia dibandingkan Malaysia. Biaya promosi pariwisata Indonesia hanya sebesar 10 juta dolar AS, sementara Malaysia mencapai 60 juta AS. Sehingga iklan Malaysia lebih sering muncul di CNN, sementara iklan Indonesia jarang ditayangkan, yang mengakibatkan orang asing kurang menyadari terhadap keberadaan Indonesia sebagai salah satu tujuan wisata.

Upaya pemerintah untuk meningkatkan citra pariwisatanya dalam mewujudkan "Indonesia The Ultimate Diversity" yaitu mengembangkan potensi pariwisata Indonesia yang terdapat di daerah-daerah dengan mengacu kepada paradigma pembangunan kepariwisataan Indonesia yang memiliki keanekaragaman sumber daya alam, budaya dan kesenian yang telah dikenal masyarakat dunia, termasuk keterbukaan, keramahan masyarakat, serta kekayaan kuliner yang unik.

Salah satu daerah yang memiliki potensi besar dalam bidang pariwisata adalah Provinsi Jawa Barat. Bidang pariwisata di Jawa Barat khususnya Kota Bandung merupakan salah satu faktor penyumbang terbesar PAD. Berbagai kebijakan yang dikeluarkan oleh pemerintah untuk memberikan kesempatan bagi investor dalam usaha kepariwisataan dan dengan adanya semangat otonomi daerah yang berlangsung di Indonesia termasuk Kota dan Kabupaten Bandung telah mendorong beberapa kalangan untuk menggali dan mengangkat potensi daerah yang ada sebagai kontribusi pembangunan kota dan peningkatan citra kota.

Bisnis yang menjanjikan dalam bidang pariwisata di Jawa Barat adalah restoran dan cafe. Pertumbuhan bisnis restoran dan café di Jawa Barat mengalami peningkatan cukup signifikan setiap tahunnya. Berdasarkan data Disbudpar Kab/Kota Jawa Barat, pertumbuhan restoran di Propinsi Jawa Barat dari tahun 1998-2004.

Salah satu daerah di Jawa Barat yang memiliki potensi dalam sektor restoran adalah Kota dan Kabupaten Bandung. Hal ini terbukti dengan semakin meningkatnya industri restoran di Kota dan Kabupaten Bandung, yang mengalami peningkatan sekitar $50 \%$ sampai $52,3 \%$ selama kurun waktu 3 tahun dan 2 tahun terakhir sejak tahun 2003 dan 2004.

Kumpulan restoran dan café tumbuh di hampir setiap sudut jalanan, di mall-mall, di komplek-komplek perumahan bahkan sampai ke daerah-daerah pelosok. Adanya peluang dalam bisnis restoran dan café telah menyebabkan industri ini berada pada tingkat persaingan yang sangat tinggi. Selain itu semangat otonomi daerah yang berlangsung di Indonesia termasuk Kota dan Kabupaten Bandung telah mendorong beberapa kalangan untuk menggali dan mengangkat potensi daerah yang ada sebagai kontribusi pembangunan kota dan peningkatan citra kota. Oleh karena itu setiap restoran dan café dituntut menerapkan strategi diferensiasi secara unik, untuk membedakan satu restoran dengan restoran lainnya, dalam upaya menciptakan keunggulan yang berkesinambungan (Duane $\mathrm{E}$ Knapp, 2001:15). Keunggulan bersaing yang berkesinambungan merupakan salah satu upaya perusahaan untuk mempertahankan loyalitas pelanggan. Karena loyalitas pelanggan memiliki peran yang strategis bagi perusahaan dalam pencapaian laba di masa depan.

Fenomena yang terjadi pada industri restoran dan café di kawasan Bandung menunjukkan tingkat loyalitas pelanggan relatif masih rendah. Memiliki pelanggan yang loyal merupakan modal untuk menjaga kelangsungan restoran dan cafe. Oleh karena itu loyalitas 
pelanggan restoran dan cafe perlu dijaga dan dipelihara serta ditingkatkan. Pelanggan yang puas dan loyal terhadap perusahaan akan siap membayar dengan harga premium, biaya promosi jauh lebih efektif dan mereka akan menjadi penyebar promosi word of mouth yang baik. Hal ini akan berpengaruh terhadap pencapaian laba masa depan.

Salah satu cara untuk meningkatkan loyalitas pelanggan adalah dengan branded customer experience. Menurut Shaun and Wheeler Joe (2003:15) "Branded customer experience merupakan salah satu kekuatan yang mendorong loyalitas pelanggan". Perusahaan dapat mencapai tujuan dengan menerapkan strategi yang sesuai, yaitu dengan menciptakan hubungan jangka panjang dengan pelanggan dan membangun serta menyentuh emosi pelanggan, sehingga pangsa yang diraih tidak hanya mind share tetapi juga mencakup heart share.

Loyalitas pelanggan juga dapat ditingkatkan melalui sentuhan emosional. Hal ini dilakukan karena mengingat pelanggan tidak hanya sebagai makhluk rasional tetapi juga emosional salah satunya adalah dengan pendekatan experiential marketing yang mengemas emosi secara komersial. Pada tahapan experiential marketing ini produsen memandang konsumen sebagai sosok yang memiliki nilai emosional yaitu satu pandangan yang menekankan adanya hubungan antara produsen dengan konsumen sampai pada tahap diterimanya pengalaman tak terlupakan oleh konsumen.

Salah satu tindakan yang dapat dilakukan restoran dan café dalam memberikan memorable experience kepada pelanggannya adalah dengan mengadakan pendekatan personal yang dapat membentuk pengalaman yang unik dan positif. Pelanggan yang terkesan dengan konsep produk yang telah ditawarkan, atau produk itu memberikan pengalaman positif yang tak terlupakan, maka pelanggan akan selalu mengingat produk tersebut dan menjadi fanatik dengan produk yang telah dibelinya.

Berdasarkan uraian masalah penelitian di atas, maka tujuan dari penelitian ini adalah untuk memperoleh temuan, yaitu:

1. Pengaruh experiential marketing yang terdiri dari dimensi sense, feel, think, act dan related dan branded customer experience terdiri dari dimensi consistent, intentional, differentiated, dan valuable terhadap loyalitas pelanggan terdiri dari dimensi behavior dan attitude pada restoran dan café di Bandung, baik secara simultan maupun parsial.

2. Pengaruh experiential marketing yang terdiri dari dimensi sense, feel, think, act dan related dan branded customer experience terdiri dari dimensi consistent, intentional, differentiated, dan valuable terhadap citra Bandung terdiri dari Bandung Kota Kembang, Bandung Kota Factory Outlet (FO), Bandung Kota Resto \& Café, Bandung Kota Jajanan dan Bandung Kota Hiburan sebagai destinasi pariwisata Indonesia, baik secara simultan maupun parsial

3. Pengaruh experiential marketing yang terdiri dari dimensi sense, feel, think, act dan related terhadap loyalitas terdiri dari dimensi behavior dan attitude serta dampaknya pada citra terdiri dari dimensi Bandung Kota Kembang, Bandung Kota Factory Outlet (FO), Bandung Kota Resto \& Café, Bandung Kota Jajanan dan Bandung Kota Bandung sebagai destinasi pariwisata Indonesia baik secara simultan maupun parsial.

4. Pengaruh branded customer experience terdiri dari dimensi consistent, intentional, differentiated, dan valuable dan loyalitas terdiri dari dimensi behavior dan attitude berpengaruh terhadap citra Bandung terdiri dari dimensi Bandung Kota Kembang, Bandung Kota Factory Outlet (FO), Bandung Kota Resto \& Café, Bandung Kota Jajanan dan Bandung Kota Bandung sebagai destinasi pariwisata Indonesia baik secara simultan maupun parsial.

Pengaruh loyalitas pelanggan terdiri dari dimensi behavior dan attitude pada restoran dan café terhadap citra Bandung Citra Bandung terdiri dari dimensi Bandung Kota Kembang, Bandung Kota Factory Outlet (FO), Bandung Kota Restoran dan Café, Bandung Kota Jajanan dan Bandung Kota Hiburan sebagai destinasi pariwisata Indonesia

\section{KERANGKA PEMIKIRAN}

Pemasar saat ini dituntut untuk menjalankan strategi pemasaran yang menarik dan mengundang perhatian banyak orang namun tetap

Experential Marketing dan Branded Customer Experience Kaitannya Dengan Loyalitas Pelanggan Restoran dan Café Serta Dampaknya Pada Citra Bandung Sebagai Destinasi Pariwisata Indonesia 
dapat memenuhi kebutuhan pelanggan akan produk dan jasa. Hal tersebut dapat dilakukan dengan cara menyentuh sensori pelanggan dibandingkan dengan rasio, yaitu dengan memberikan sentuhan experiential (pengalaman yang mengesankan). Strategi pemasaran experiential, di mana pasar tidak lagi melakukan permintaan akan barang dan jasa yang berkualitas, tetapi juga manfaat emosional berupa pengalaman tak terlupakan (memorable experience) yang mempererat hubungan pelanggan dengan produsen melalui produk yang ditawarkan. Strategi pemasaran tersebut dinilai lebih efektif bagi pelanggan karena memberikan pengalaman yang luar biasa, sehingga pelanggan tidak hanya tertarik kepada fungsi produk atau jasa saja, melainkan pengalaman unik yang diterima dari produk atau jasa tersebut.

Gagasan experiential marketing dikenalkan oleh Bernd H. Schmitt (1999:3). Menurutnya di tengah era revolusi pemasaran ini strategi experiential marketing akan menggeser pendekatan tradisional yang menekankan pada fitur dan benefit produk, serta memandang pelanggan sebagai sosok yang rasional. Pendekatan tradisional tanpa melibatkan unsur emosi dan pengalaman merupakan strategi yang rentan, mudah ditiru atau diserang oleh produk serupa.

Pendapat Bernd $\mathrm{H}$. Schmitt, sejalan dengan apa yang dikemukakan oleh Janelle Barlow dan Diana Maul (2000), Valerie A.Zeithalm dan Mery Jo Bitner (2006) dan Kotler (2003) yang menyatakan bahwa unsur emosi, merupakan salah satu pendorong penciptaan nilai pelanggan. Menurut Janelle Barlow dan Diana Maul (2000:2) dan Kotler (2003:13) bahwa emotional value merupakan nilai ekonomi atau nilai moneter dari perasaan ketika pelanggan mendapatkan pengalaman yang positif dengan produk dan jasa suatu organisasi.

Pendekatan experiential marketing menghadirkan pengalaman-pengalaman yang unik, positif dan mengesankan yang membentuk memorable experience bagi pelanggan. Pengalaman tak terlupakan tersebut adalah nilai berupa emotional benefit (manfaat emosional) yang ditawarkan sesuai dengan kebutuhan pelanggan dan menjadi keunggulan perusahaan yang sulit ditiru oleh pesaing. Scott Robinette dan Claire Brand (2001:60) mengungkapkan bahwa "experience is the collection of points at wich companies and consumers axchange sensory stimuli, information and emotion". Pengalaman adalah kumpulan dari poin-poin di mana pelanggan dengan perusahaan saling bertukar rangsangan panca indera, informasi dan emosi.

Kerangka kerja konseptual experiential marketing terbagi menjadi dua konsep yaitu strategic experiential modules (SEMs) yang merupakan pondasi experiential marketing dan experiences providers (ExPro's) sebagai alat taktis pelaksanaan experiential marketing.

Experiential modules (SEMs) mendeskripsikan lima tipe tahapan pengalaman yang merupakan bentuk dasar experiential marketing frame work, yaitu sense, feel, think, act dan relate.

Pertama sense (panca indera pelanggan), bertujuan untuk menciptakan pengalaman yang mengikat panca indera melalui penglihatan, suara, sentuhan, perasaan, penciuman yang memberikan kesan keindahan, kesenangan dan kepuasan. Kedua, feel (perasaan pelanggan) bertujuan untuk menyentuh perasaan/emosi dengan sasaran pembangkitkan pengalaman efektif. Ketiga, think (pemikiran pelanggan) bertujuan menciptakan image positif (aspek kognitif), Keempat, act (aksi yang dilakukan pelanggan), bertujuan untuk menyentuh pengalaman dalam gaya hidup dan berinteraksi. Kelima, relate (hubungan pelanggan dan perusahaan) bertujuan untuk memberikan pengalaman individual dalam berhubungan dengan orang lain dalam budaya/kebiasaan/gaya hidup tertentu.

Experiential providers (ExPro's) menjelaskan bagaimana SEMs dapat dibentuk melalui contact point antara produsen dan pelanggan di mana ExPro's ini adalah medium yang mampu mengoptimalkan rangsangan SEMs. Media yang digunakan dapat berupa communications visual/verbal identity, product presence, cobranding, spatial environment, electronic media dan people. (Bernd H. Schmitt (1999:60). Hal tersebut sejalan dengan pendapat Scot Robinette dan Claire Brand (2001:61) bahwa pengalaman yang merangsang keseluruhan panca indera manusia dapat diperolehnya melalui: pengalaman dengan produk, pengalaman dengan lingkungan, pengalaman dengan komunikasi/hubungan, pengalaman dengan pelayanan dan hubungan sosial dan pengalaman dengan kegiatan (event). 
Dalam pelaksanaannya baik Bernd H. Schmitt dan Scot Robinette \& Claire Brand menyatakan pengalaman yang terbaik adalah pengalaman holistik atau pengalaman yang dapat merangsang keseluruhan panca indera manusia.

Nilai emosi yang harus diberikan kepada pelanggan berbeda-beda antara satu industri dengan industri lainnya. Menurut Edwardson dalam Janelle Barlow Dianna Maul (2000:161) untuk menciptakan nilai emosional (emotional value) bagi pelanggan dalam membentuk hubungan jangka panjang pada hospitality industry (café, restoran, dan pub) adalah suasana rileks (positif), bila nilai tersebut tidak dapat diciptakan maka akan membentuk emosi negatif (kekecewaan). Oleh karena itu perusahaan harus dapat mengetahui nilai-nilai yang diinginkan oleh pelanggan dengan memperhatikan faktor-faktor utama yang dipertimbangkan pelanggan dalam memilih restoran dan café.

Berdasarkan hasil beberapa penelitian mengenai faktor-faktor yang mempengaruhi proses keputusan pelanggan dalam memilih restoran dan café menunjukkan adanya perbedaan. Menurut Lewis (1981) terdapat lima faktor pilihan restoran dan café yaitu: kualitas makanan, variasi menu, harga, atmosfir dan faktor kenyamanan. Tingkatan faktor-faktor tersebut bervariasi, tergantung dari jenis/ tipe restoran, di mana pada kasus Lewis kategori tersebut bergabung dengan tipe makanan, pilihan keluarga/popularitas, atmosfir dan jenis makanan. Namun pertimbangan yang paling utama terhadap pemilihan makanan dipengaruhi oleh kualitas makanan.

Penelitian lainnya dilakukan oleh After Auty (1987) yang memiliki kesamaan dengan penelitian dari June \& Smith (1987), menghasilkan 10 peringkat dan bobot dari faktor penting dalam pemilihan restoran dan café yaitu; 1) tipe makanan (71), 2) kualitas makanan (59), 3) harga (46), 4) image dan atmosfir (33), 5) lokasi (32), 6) kecepatan pelayanan $(15), 7$ ) hasil rekomendasi $(11), 8)$ pengalaman baru $(8)$, 9) jam operasi (waktu buka) (8), 10) fasilitas untuk anak-anak (8).

Demikian halnya dengan penelitian Mona A Clark dan Roy C Wood (1999:323), membagi 10 aspek yang menjadi pilihan pelanggan beserta skornya dalam restoran dan café, yaitu: 1) harga makanan (90), 2) harga minuman (84), 3) kecepatan pelayanan (84), 4) kualitas makanan
(84), 5) Atmosfir (84), 6) keramahan petugas (87), 7) fasilitas parkir (55), 8) fasilitas penunjang (66), 9) pilihan menu makanan (84) dan 10) jam buka (83). Berdasarkan 10 aspek tersebut, terdapat lima aspek yang dianggap paling penting oleh responden, yaitu, 1) variasi makanan, 2) kualitas makanan, 3) harga, 4) atmosfir dan 5) kecepatan pelayanan.

Berdasarkan beberapa hasil penelitian pemilihan terhadap restoran, maka program Strategic Experiential Modules (SEMs) yang dipersepsikan pelanggan restoran dan café pada penelitian ini menggunakan lima pendekatan yang dikemukakan oleh Bernd H. Schmitt yaitu sense, feel, think, act dan relate. Sedangkan experiential providers (ExPros) dengan menggunakan kombinasi dari beberapa ahli (Schmitt, Mona A Clark dan Roy C Wood, Lewis, After Auty, June dan Smith) yang terdiri dari; variasi makanan, kualitas makanan, atmosfir, kecepatan melayani, value, kenyamanan, dan lay out (untuk mengukur sense, feel, think dan act). Prestige, identitas dan kelas sosial digunakan untuk mengukur related.

Pengalaman emosional pelanggan akan produk dan jasa yang unik dan positif yang tak terlupakan (memorable experience) perlu dikemas dalam sebuah branding. Semua produk memerlukan usaha pembentukan merek (branding) agar bersaing untuk mendapatkan pelanggan. (Kiki Kaplanidao dan Christine Vogt (2003:1). Branding adalah janji kepada pelanggan, suatu harapan mengenai kinerja dan tanda integritas dan reputasi (Travis, 2000). Branding akan terus menerus tertanam di dalam benak pelanggan yang dipengaruhi oleh pengalaman, ingatan dan word of mouth dari pelanggan lain. Oleh karena itu branding perlu mempunyai unsur-unsur unik, yang membedakannya dari pesaing dan membentuk citra di benak pelangan.

Riset yang dilakukan oleh Wunderman Brand Experience/ Scorecard, kepada lebih dari 10.000 pelanggan melibatkan 1993 merek dari 190 perusahaan, menunjukkan selama lebih dari dua tahun (2000-2002), bahwa dari hari ke hari pengalaman pelanggan memainkan peranan yang penting dalam pembangunan merek. Temuan yang terpenting dalam penelitian ini bahwa penilaian kinerja suatu merek tidak hanya berdasarkan persepsi merek, tetapi pada pengalaman aktual pelanggan. Dengan demikian para pemasar harus

Experential Marketing dan Branded Customer Experience Kaitannya Dengan Loyalitas Pelanggan Restoran dan Café Serta Dampaknya Pada Citra Bandung Sebagai Destinasi Pariwisata Indonesia 
membuat sebuah metode pemahaman baru dalam menyusun "visi merek" dengan menggunakan kerangka "brand experience" (Susan Fournier dan Kevin Keller dalam Journal Wunderman Brand Experience/Scorecard, 2004:4)

Menurut Smith dan Wheeler (2002:10), "Terdapat dua cara agar perusahaan dapat menciptakan pengalaman bagi pelanggan, yang pertama adalah experiencing the brand dan kedua adalah branding the experience". Proses experiencing the brand adalah mengkomunikasikan perusahaan (brand essense), kemudian menterjemahkannya ke dalam brand promises yaitu nilai yang ingin disampaikan perusahaan. Pada saatnya brand promise akan menjadi branded customer experience di mana perusahaan memberikan atau memenuhi brand promises-nya pada setiap interaksi pelanggan dengan people, processes, dan products. Setelah branded customer experience terbentuk, maka muncul brand value atau nilai yang diharapkan oleh pelanggan. Dalam jangka panjang, brand value akan membentuk brand image.

Michael Bates dalam Smith dan Wheeler (2002:12) mengemukakan dimensi dalam pengukuran branded customer experience antara lain: 1) Consistent: menawarkan atau menyampaikan pengalaman akan waktu dan lokasi. 2) Intentional: menawarkan atau menyampaikan pengalaman pelanggan untuk mendukung merek. 3) Differentiated: merupakan perbedaan dari merek pesaing dan 4) Valuable: menawarkan atau menyampaikan a customer proposition yang mana menemukan target kebutuhan pelanggan.

Keempat dimensi branded customer experience tersebut, akan memberi pengalaman yang unik pada industri restoran dan café, seperti dikemukakan oleh Shaun Smith (2002:1), bahwa:

"...this trend is crossing over the service sector. From hotels to restaurant to airlines, consumers are looking for suplier who go beyond the basics to meet their unique needs. They are looking for what we at Forum call Branded Customer Experience, a service experience that is intentional, consistent, differentiated, and valuable

Selanjutnya dari keempat dimensi branded customer experience tersebut, diimplementasikan di dalam pengukuran kinerja restoran dan café dengan melibatkan indikator didalamnya yaitu variasi makanan, rasa makanan, atmosfir, kecepatan melayani, value, fasilitas pendukung, lay out. Melalui indikator-indikator tersebut diharapkan dapat mengukur kualitas dari pengalaman pelanggan terhadap merek restoran dan café yang dikunjunginya.

Harga dalam penelitian ini tidak dimasukkan ke dalam salah satu indikator alasan pelanggan memilih restoran dan café, hal ini dikarenakan penelitian ini dilakukan pada hari week end atau hari libur, sehingga pelanggan kurang mementingkan harga dalam pemilihan restoran dan café. Hal ini sesuai dengan penelitian Mona A. Clark \& Roy C. Wood (1999:319) :

Customer will evaluate a restaurant as a place to eat-out or as a place to dine-out. If a restaurant is considered an eat-out operation during the week (a substitute for cooking at home), customers will be more price conscious. If a restaurant is considered a dine out operation, the visit is regarded more as a social occasion or entertainment and price is not as much of a factor.

Perusahaan dapat memberikan pengalaman yang unik dan positif (memorable experience) kepada pelanggan, hal ini dapat menciptakan loyalitas. Seperti yang diungkapkan oleh Smith dan Wheeler (2002:17) bahwa "Branded customer experience merupakan salah satu kekuatan mendorong loyalitas pelanggan". Secara lengkap proses penciptaan loyalitas berdasarkan pegalaman pelanggan disajikan dalam Gambar 1 sebagai berikut

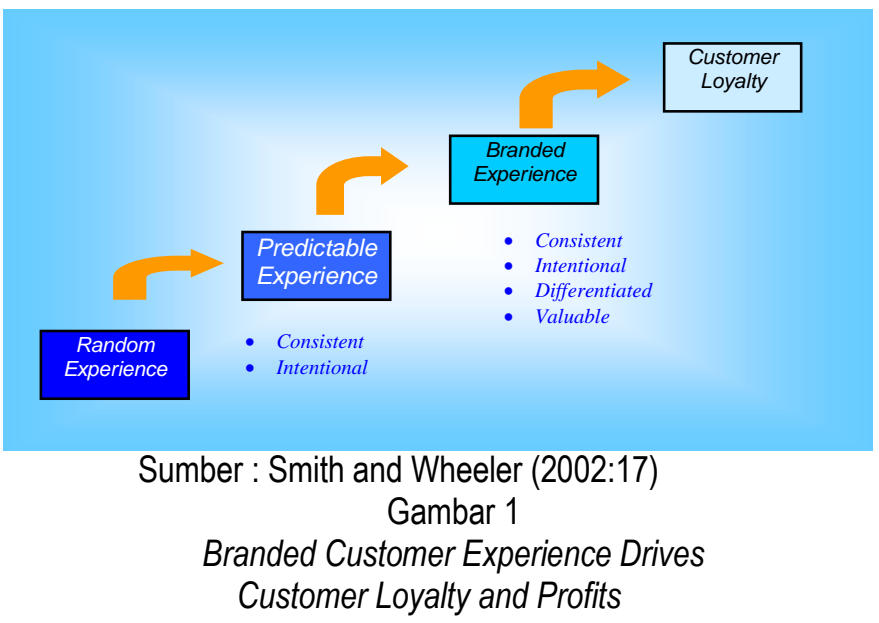

Menurut Oliver (1997:392) menjelaskan bahwa "Loyalitas pelanggan adalah komitmen untuk 
bertahan secara mendalam untuk melakukan pembelian ulang atau berlangganan kembali produk atau jasa terpilih secara konsisten di masa yang akan datang, meskipun pengaruh situasi dan usaha-usaha pemasaran mempunyai potensi untuk menyebabkan perubahan perilaku".

Griffin (2004:4) dan John Egan (2001:4) mengatakan bahwa konsep loyalitas lebih mengarah kepada perilaku (behaviour) dibandingkan dengan sikap (attitude) dan seorang pelanggan yang loyal akan memperlihatkan perilaku pembelian yang dapat diartikan sebagai pola pembelian yang teratur dan dalam kurun waktu yang lama, yang dilakukan oleh unit-unit pembuat dan pengambil keputusan. Sedangkan menurut William G. Zikmund et. al (2002:72) faktorfaktor yang mempengaruhi loyalitas pelanggan atau komponen-komponen sikap dan perilaku dalam loyalitas pelanggan antara lain customer satisfaction, emotional bonding, trust, choice reduction and habit, history with the company.

Berdasarkan perspektif perilaku, loyalitas diartikan sebagai pembelian ulang suatu merek secara konsisten oleh pelanggan. Setiap kali seorang pelanggan membeli ulang suatu produk/jasa dengan merek yang sama, maka ia dikatakan loyal pada merek tersebut. Perspektif behavioral mengukur perilaku pembelian efektif, namun tidak mampu menjelaskan apakah pembelian ulang yang terjadi karena faktor kebiasaan, alasan-alasan situasional, atau alasanalasan psikologis yang lebih kompleks.

Perspektif sikap, asumsi utamanya adalah bahwa terdapat sejumlah kecil faktor eksplanatoris yang mempengaruhi loyalitas. Loyalitas tidak dipandang sebagai dikotomi antara loyal dan tidak loyal, namun lebih sebagai kontinum (a degree of loyalty). Tujuan utama pengukuran loyalitas menurut perspektif sikap bukanlah untuk mengetahui apakah seseorang loyal atau tidak, namun untuk memahami intensitas loyalitasnya terhadap suatu produk atau jasa tertentu. Hanya bila pelanggan lebih positif (favorable) terhadap merek produkjjasa tertentu dibandingkan merekmerek lain, maka ia dikatakan loyal terhadap merek yang bersangkutan. Perspektif sikap dari loyalitas pelanggan termasuk niat dan preferensi pelanggan. Sikap seperti niat membeli ulang dan niat merekomendasikan dianggap suatu indikator loyalitas pelanggan.
Menurut William G. Zikmund et.al (2002:70) bahwa: "Pendekatan loyalitas melalui sikap melihat bahwa keterlibatan loyalitas lebih besar daripada perilaku pengulangan pembelian. Jadi pandangan ini berpedoman bahwa yang dimaksud loyalitas didalamnya termasuk sikap menyukai yang direfleksikan/ ditunjukkan dengan komitmen yang diekspresikan setiap saat. Sikap berkaitan dengan penilaian objek dan sikap berkaitan dengan memo/saran untuk membeli yang menunjukkan adanya pengalaman emosional".

Tujuan terciptanya loyalitas pelanggan menurut Uncles, at.all (2003) adalah pertama untuk meningkatkan pendapatan perusahaan melalui pembelian ulang atau pemakaian. Tujuan yang kedua lebih kepada upaya mempertahankan kelangsungan perusahaan dengan membangun ikatan yang lebih kuat antara merek (brand) dengan pelanggan. Merek tidak sekedar sebuah logo atau merek dagang. la memasukkan banyak komponen yang bekerja sama untuk membentuk konsep merek daerah tujuan. Komponenkomponen tersebut menurut Kiki Kaplanidao dan Christine Vogt (2003:3) adalah brand identity, brand image, brand personality, brand essencelbrand soul, brand character dan brand culture.

Ketika suatu merek muncul dalam pikiran pelanggan, hal ini dapat mendorong pengasosiasian dengan tujuan yang lebih kecil dalam wilayah penerapan merek tersebut, tetapi hal yang pertama yang harus dimunculkan adalah kekonsistenan dari citra merek (brand image).

Kotler dan Armstrong (2006:268), pengertian brand image itu adalah sebagai berikut: "Brand image is the perceptions and beliefs held by consumers, as reflected in the associations held in consumer memory". Citra (image) pada suatu produk dapat diukur melalui pendapat, kesan, tanggapan seseorang dengan tujuan untuk mengetahui secara pasti apa yang ada dalam pikiran setiap individu mengenai suatu objek, bagaimana mereka memahaminya dan apa yang mereka sukai atau tidak dari objek tersebut.

Suatu citra merek dibangun dari asosiasiasosiasi merek tersebut. Hal ini sesuai dengan pendapat Keller (2003:70) yang menyatakan bahwa, Brand image dibangun dari asosiasi tentang organisasi dari suatu merek, product, the country of origin, the brand personality, dan the

Experential Marketing dan Branded Customer Experience Kaitannya Dengan Loyalitas Pelanggan Restoran dan Café Serta Dampaknya Pada Citra Bandung Sebagai Destinasi Pariwisata Indonesia 
brand artifacs. Asosiasi ini tidak hanya mempengaruhi dalam menciptakan brand image, tapi juga mempengaruhi satu sama lain. Maka demikian asosiasi itu merupakan suatu keterhubungan antara bagian brand image, sehingga merek menjadi lebih positif, bersifat sangat unik dan dapat dengan mudah diingat oleh pelanggannya.

Asosiasi merek tersebut dapat didefinisikan sebagai segala kesan yang muncul dibenak seseorang yang terkait dengan ingatannya mengenai suatu merek (Aaker, 1997:160). Asosiasi merek yang ingin diketahui dapat dibangkitkan dengan mempertimbangkan berbagai asosiasiasosiasi yang terkait dengan suatu merek produk. Menurut Keller (2003:70-73) bahwa asosiasi terdiri dari beberapa jenis yaitu favorable (harus disukai), uniqueness (memiliki keunikan) dan strength (diperkuat). Favorable artinya suatu asosiasi harus memiliki daya tarik dan disukai oleh pelanggan. Dengan demikian maka tingkat kemenarikan asosiasi merek dapat mempengaruhi citra yang terbentuk. Jenis asosiasi lainnya adalah uniqueness yaitu keunikan. Keunikan suatu asosiasi yang ada pada merek dapat memberikan nilai tambah, hal ini diakibatkan dari keunikan yang dimiliki menjadi pembeda dari produk yang sama dari merek pesaing. Oleh karena itu semakin baik keunikan yang dimiliki oleh suatu merek maka citra yang terbentuk pun akan semakin baik. Asosiasiasosiasi pada suatu merek juga harus diperkuat agar dapat menjaga citra yang terbentuk melalui atribut, benefit dan simbol yang dimiliki oleh merek tersebut.

Asosiasi-asosisasi tersebut mencerminkan kedudukan suatu merek dan merupakan janji kepada para pelanggan yang diberikan oleh anggota organisasi. Citra merek akan membantu memantapkan hubungan antara merek dan pelanggan melalui prosisi nilai yang melibatkan manfaat fungsional, manfaat emosional atau ekspresi diri. Citra merek memberikan prosisi merek kepada pelanggan dan memberikan kredibilitas terhadap merek lain. Citra merek dapat membantu penyusunan strategi untuk mengatasi kendala tersebut serta menciptakan referensi bagi pelanggan ketika mereka mengevaluasi merek dan para pesaingnya.

Konsep teori citra merek maka dalam penelitian ini citra merek Bandung merupakan akumulasi dari dilihat dari favorable, uniqueness dan strength pada asosiasi-asosiasi pelanggan restoran dan café di Bandung, yaitu Bandung Kota Kembang, Bandung Kota Hiburan dan Wisata, Bandung Kota Jajanan, Bandung Kota Factory Outlet dan Bandung Kota Restoran dan Café.

\section{METODE PENELITIAN}

Penelitian ini bersifat deskriptif dan verifikatif. Penelitian deskriptif bertujuan untuk memperoleh gambaran mengenai variabel yaitu experiential marketing, branded customer experience, loyalitas pelanggan, dan citra Bandung. Sedangkan penelitian verifikatif untuk menguji pengaruh experiential marketing dan branded customer experience terhadap loyalitas pelanggan restoran dan cafe serta dampaknya pada citra Bandung sebagai destinasi pariwisata Indonesia. Unit analisis dalam penelitian ini adalah restoran dan cafe di Bandung. Sedangkan unit observasinya adalah pelanggan restoran dan cafe di Bandung. Pengamatan menggunakan cakupan waktu (time horizon) bersifat cross section/one shoot.

Ukuran populasi dalam penelitian ini sebesar 7026 pelanggan restoran dan cafe di Bandung. Jumlah tersebut diperoleh dari rata-rata kunjungan pelanggan/hari dalam waktu weekend (Sabtu/Minggu atau hari libur) dari 36 restoran dan cafe di Bandung Sedangkan ukuran sampelnya sebesar 375 orang dipilih dari masing-masing restoran dan cafe secara proposional.

Teknik pengumpulan data dilakukan melalui wawancara, kuesioner, dokumentasi, dan observasi. Untuk dapat memjawab pertanyaan penelitian dan menilai model yang disusun, teknik analisis yang digunakan adalah Structural Equation Model (SEM) dengan menggunakan program Lisrel 8.30 (Joreskog,1996). Model persamaan struktural yang digunakan adalah :

$$
\begin{array}{r}
\text { Model 1: } Y_{1}=\Gamma X+\zeta_{1} \\
\text { Model 2: } Y_{2}=\Gamma X+\mathrm{B} Y+\zeta_{2} \\
\text { Model } 3: Z=\Gamma X+\mathrm{B} Y+\mathrm{B} Y_{2}+\zeta_{3} \\
\text { Oleh karena dalam model persamaan } \\
\text { struktural di atas menggunakan beberapa konstruk } \\
\text { eksogen dan konstruk endogen, maka sebelum } \\
\text { penggunaan SEM terlebih dahulu dilakukan } \\
\text { pengujian terhadap konstruk-konstruk tersebut. }
\end{array}
$$




\section{HASIL PENELITIAN DAN PEMBAHASAN}

Analisis model struktural (Structural Model Analysis) dibangun oleh hubungan antar variabel laten (konstruk) yang indikator-indikator serta konstruknya telah diuji validitas dan reliabilitasnya pada model pengukuran.

Tabel 2

Pengujian Model Penelitian

\begin{tabular}{|c|c|c|}
\hline $\begin{array}{c}\text { Ukuran Goodness } \\
\text { of Fit Test }\end{array}$ & Statistik & Hasil Uji \\
\hline Chi-Square & 121,61 & \multirow{9}{*}{$\begin{array}{c}\text { Model } \\
\text { mengindikasikan fit } \\
\text { dengan data } \\
(\rho>0,05 ; \text { RMSEA }< \\
0,08 ; \text { GFI dan } \\
\text { NNFI > 0,90) }\end{array}$} \\
\hline Derajat Kebebasan & 98 & \\
\hline Nilai $p$ & 0,05327 & \\
\hline RMSEA & 0,023 & \\
\hline GFI & 0,96653 & \\
\hline AGFI & 0,95356 & \\
\hline NFI & 0,93867 & \\
\hline NNFI & 0,98596 & \\
\hline CFI & 0,98853 & \\
\hline
\end{tabular}

Sumber : Hasil Pengolahan dengan LISREL 8.30

Tabel 3 menunjukkan bahwa nilai Chi-Square sebesar 121,61 dengan derajat bebas 98 dan RMSEA sebesar $0,023<0,08$ sehingga mengisyaratkan bahwa model teoritis dan konseptual pada diagram jalur didukung oleh data empirik, sehingga dapat diterima pada taraf signifikansi $5 \%$. Pengujian secara deskriptif memperlihatkan hasil nilai CFI sebesar 0,98853, AGFI sebesar 0,95356, dan nilai NNFI sebesar 0,98596 mendekati satu sehingga model dapat diterima. Sesuai dengan Hair, Anderson, Tatham, dan Black (1998:622) apabila indeks kecocokkan (goodness of-fit indices, GFI) lebih besar atau sama dengan 0,9 maka model dapat diterima. Kesimpulan yang dapat diambil dari hasil penilaian kesesuaian model struktural adalah bahwa model telah mencapai kesesuaian dan dapat digunakan untuk analisis hubungan antar konstruk serta pengujian hipotesis.

Karena model penelitian sudah dapat diterima secara empirik, maka selanjutnya dilakukan uji hipotesis dengan paket program LISREL 8.30. Hasil pengujian hipotesis disajikan dalam Gambar 1 sebagai berikut.

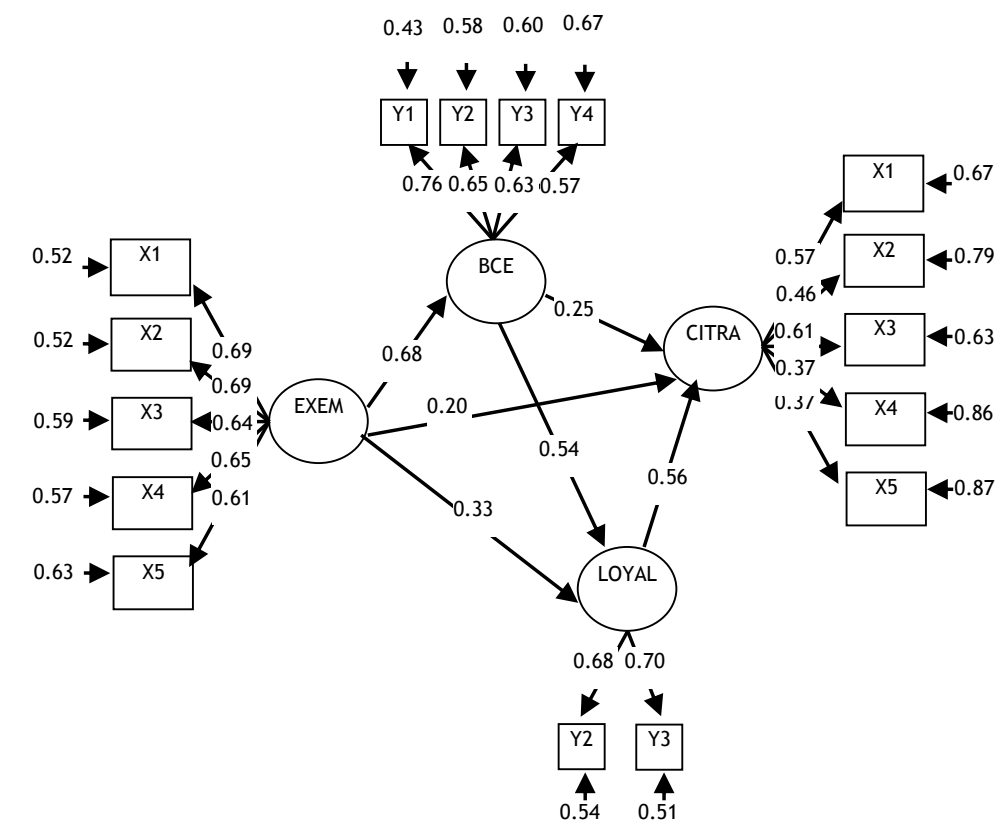

Chi- Square $=121.61, \mathrm{df}=98, \mathrm{P}$-Value $=0.05327, \mathrm{RMSEA}=0.023$

\section{Gampar 2}

Persamaan Struktural Pengaruh Experiential Marketing dan BCE terhadap Loyalitas Pelanggan Restoran dan Cafe serta Dampaknya pada Citra Bandung sebagai Destinasi Pariwisata Indonesia (Standardized)

Berdasarkan gambar di atas dapat dilihat bahwa pengaruh experiential marketing terhadap BCE secara langsung adalah sebesar 0,4624 atau sebesar $46,24 \%$. Pengaruh langsung experiential marketing terhadap loyalitas pelanggan adalah sebesar $(0,33)^{2}=0,1089$ atau sebesar $10,89 \%$, sedangkan pengaruh tidak langsung experiential marketing terhadap loyalitas pelanggan melalui BCE adalah sebesar $(0,68 \times 0,54)=0,3672$ atau sebesar $36,72 \%$. Total pengaruh experiential marketing dan BCE terhadap loyalitas pelanggan baik langsung maupun tidak langsung adalah sebesar 0,9385 atau $93,85 \%$. Sisanya, yaitu sebesar 0,615 atau 6,15\% loyalitas pelanggan dipengaruhi oleh variabel lain di luar variabel experiential marketing dan BCE.

Pengaruh experiential marketing terhadap BCE secara langsung adalah sebesar 0,4624 atau sebesar $46,24 \%$. Pengaruh langsung experiential marketing terhadap citra Bandung adalah sebesar $(0,20)^{2}=0,0400$ atau sebesar $4 \%$, pengaruh langsung BCE terhadap citra Bandung adalah 
sebesar $(0,25)^{2}=0,0625$ atau sebesar 6,25\%, sedangkan pengaruh tidak langsung experiential marketing terhadap citra Bandung melalui BCE adalah sebesar $(0,68 \times 0,25)=0,1700$ atau sebesar $17 \%$. Total pengaruh experiential marketing terhadap BCE serta dampaknya pada citra Bandung sebagai destinasi pariwisata baik langsung maupun tidak langsung adalah sebesar 0,7349 atau $73,49 \%$. Sisanya, yaitu sebesar 0,2651 atau $26,51 \%$ citra Bandung sebagai destinasi pariwisata Indonesia dipengaruhi oleh variabel lain di luar variabel experiential marketing dan BCE.

Pengaruh experiential marketing terhadap loyalitas pelanggan secara langsung adalah sebesar 0,1089 atau sebesar $10,89 \%$. Pengaruh langsung experiential marketing terhadap citra Bandung adalah sebesar $(0,20)^{2}=0,0400$ atau sebesar $4 \%$, sedangkan pengaruh tidak langsung experiential marketing terhadap citra Bandung melalui loyalitas pelanggan adalah sebesar $(0,33 \mathrm{X}$ $0,56)=0,1848$ atau sebesar $18,48 \%$. Total pengaruh experiential marketing terhadap loyalitas pelanggan serta dampaknya pada citra Bandung sebagai destinasi pariwisata baik langsung maupun tidak langsung adalah sebesar 0,2941 atau $29,41 \%$. Sisanya, yaitu sebesar 0,7059 atau $70,59 \%$ citra Bandung sebagai destinasi pariwisata Indonesia dipengaruhi oleh variabel lain di luar variabel experiential marketing dan loyalitas pelanggan.

Pengaruh langsung $B C E$ terhadap citra Bandung adalah sebesar $(0,20)^{2}=0,0400$ atau sebesar 4\%, Pengaruh langsung loyalitas pelanggan terhadap citra Bandung adalah sebesar $(0,56)^{2}=0,3136$ atau sebesar $31,36 \%$, sedangkan pengaruh tidak langsung $B C E$ terhadap citra Bandung melalui loyalitas pelanggan adalah sebesar $(0,54 \times 0,56)=0,3024$ atau sebesar $30,24 \%$. Total pengaruh $B C E$ dan loyalitas pelanggan terhadap citra Bandung sebagai destinasi pariwisata baik langsung maupun tidak langsung adalah sebesar 0,656 atau $65,6 \%$. Sisanya, yaitu sebesar 0,344 atau $34,4 \%$ citra Bandung sebagai destinasi pariwisata Indonesia dipengaruhi oleh variabel lain di luar variabel $B C E$ dan loyalitas pelanggan.

Besarnya pengaruh loyalitas pelanggan terhadap citra Bandung adalah sebesar $(0,56)^{2}=$ 0,3136 atau sebesar $31,36 \%$.
Hasil temuan yang telah diuraikan di atas diperkuat oleh Himawan (2004:86) "merek akhirnya akan menjelma menjadi sebuah keyakinan berlandaskan nilai yang terkandung dalam merek tersebut. Kinerja merek akan berkaitan dengan kemampuannya untuk memberikan hal yang menarik bagi konsumen, dan timbulnya loyalitas merek akan memberikan kontribusi yang sangat berarti bagi perusahaan". A.B Susanto juga mengungkapkan (2004:299) mengungkapkan bahwa citra merek terutama terbentuk oleh pengalaman pelanggan dalam berhubungan dengan perusahaan, yang diwakili oleh merek dan ditopang oleh organisasi yang berada di belakangnya, serta dijembatani oleh brand promise. Selanjutnya A.B Susanto, (2004:301) juga mengungkapkan bahwa kultur merek yang tercipta dalam masyarakat akan membentuk pola perilaku yang konsisten dan sesuai dengan brand promise. Perilaku yang konsisten ini akan dirasakan sebagai pengalaman merek oleh konsumen dan akan membentuk citra merek di mata mereka.

Selanjutnya Kandampully dan Suhartanto (2000) dalam Usmara (2003:272) menjelaskan pentingnya mempertahankan brand image dan meningkatkan kepuasan konsumen untuk mempertahankan loyalitas konsumen.

\section{KESIMPULAN DAN SARAN}

\section{Simpulan}

Berdasarkan pembahasan hasil penelitian dapat ditarik kesimpulan bahwa:

1. Experiential marketing dan branded customer experience berpengaruh terhadap loyalitas pelanggan restoran dan café di Bandung. Di mana pengaruh experiential marketing melalui branded customer experience terhadap loyalitas lebih besar, dibandingkan pengaruh langsung dari experiential marketing. Hal ini menunjukkan bahwa perusahaan harus dapat mengemas sebuah pengalaman yang unik dan memorable pada sebuah merek yang ditawarkan kepada pelanggan.

2. Experiential marketing, branded customer experience, berpengaruh terhadap citra Bandung sebagai salah satu destinasi pariwisata di Indonesia. Di mana pengaruh langsung experiential marketing terhadap citra relatif lebih kecil dibandingkan pengaruh experiential marketing melalui branded 
customer experience. Hal ini menggambarkan bahwa pengalaman yang positif dan tidak terlupakan dapat meningkatkan citra suatu wilayah.

3. Loyalitas pelanggan restoran dan café berpengaruh terhadap citra Bandung sebagai Destinasi Pariwisata Indonesia. Pentingnya menjaga loyalitas pelanggan berdampak kepada peningkatan citra suatu wilayah dan akhirnya secara langsung dapat meningkatkan kunjungan wisatawan.

\section{Saran}

Saran yang Berkaitan dengan Pengembangan IImu

1. Berdasarkan penelitian dalam disertasi ini dilakukan terhadap pelanggan individu restoran dan café, maka dinilai perlu dilakukan penelitian terhadap pelanggan bisnis restoran dan café guna memperoleh perbandingan yang dapat dijadikan patokan dalam mengembangkan experiental marketing dan branded customer experience pada bisnis restoran dan café.

2. Diperlukannya penelitian lanjutan yang meneliti mengenai faktor-faktor lain yang turut berperan dalam menciptakan pengalaman yang unik dan memorable bagi pelanggan restoran dan cafe yang berpengaruh pada terciptanya loyalitas pelanggan serta dampaknya pada pembentukan citra merek, yang belum mampu dilakukan peneliti dalam penulisan disertasi ini.

3. Perlu dilakukan penelitian mengenai pengalaman dan perilaku pelanggan terhadap jenis-jenis atau tipe-tipe restoran dan cafe berdasarkan kesukaannya. Seperti berdasarkan tipe restoran keluarga, restoran tempat hiburan, restoran fast foods dan lainnya.

4. Dalam mengembangkan citra Bandung sebagai Kota Restoran dan Cafe, perlu dilakukan penelitian lebih mendalam mengenai pengalaman dan perilaku yang dirasakan oleh wisatawan terhadap kinerja restoran dan cafe, serta upaya yang dilakukan pemerintah Kota dan Kabupaten Bandng dalam mengembangkan industri restoran dan cafe tersebut.

\section{Saran yang Berkaitan dengan Manajerial}

1. Dalam meningkatkan experiential marketing maka pemilik restoran dan cafe disarankan untuk melakukan perbaikan:

a. Mereposisioning bentuk bangunan sesuai dengan visi dan misi yang ditawarkan oleh masing-masing restoran dan cafe yang ditunjang oleh desain interior yang sesuai.

b. Mengadakan pendidikan dan pelatihan bagi karyawan sehingga dapat melayani pelanggan dengan baik, cepat dan tepat. Agar penampilan karyawan terlihat unik dan tidak sama dengan restoran dan cafe lain maka sebaiknya karyawan memakai seragam yang didesain lain dengan restoran dan cafe lain.

C. Menambah variasi makan dan minuman yang ditunjang dengan rasa yang enak. Hal ini dibisa dilakukan dengan cara menambah koki-koki yang sudah berpengalaman serta memberikan pendidikan dan pelatihan bagi koki agar dapat menciptakan makanan yang enak dan lezat.

d. Meyajikan berbagai jenis hiburan yang bervariasi sehingga pelanggan tidak akan merasa bosan. Pertunjukan live music dengan kolaborasi instrumen musik dari berbagai jenis, misalnya: memasukkan alat gamelan pada instrumen sejenis band, musik keroncong, siteran, dan lain sebagainya. Mengikutsertakan atau melibatkan pelanggan dalam penyajian entertainment (entertainment by participation) misalnya: pelangan ikut menari, menyanyi, dan lain-lain juga dapat menjadi alternatif.

e. Menambah fasilitas penunjang (misalnya penambahan toilet, mushola, sarana parkir, dan lain-lain) serta memelihara kebersihan dan kenyamanan fasilitas penunjang tersebut.

f. Berusaha menciptakan hubungan baik dengan pelanggan. Hal ini dapat dilakukan dengan menetapkan segmen yang akan dijadikan sasaran kemudian membuat restoran dan cafe menjadi tempat berkumpul komunitas pelanggan

Experential Marketing dan Branded Customer Experience Kaitannya Dengan Loyalitas Pelanggan Restoran dan Café Serta Dampaknya Pada Citra Bandung Sebagai Destinasi Pariwisata Indonesia 
sasaran, misalnya dengan cara memfasilitasi pelanggan sesuai dengan hobinya.

2. Dalam meningkatkan branded customer experience, penulis menganjurkan kepada pihak restoran dan café agar menjaga konsistensi baik dalam hal desain eksterior, interior, karyawan, variasi dan rasa makanan serta minuman, hiburan maupun fasilitas penunjang sehingga sesuai dengan poisistioning restoran dan cafe. Selain itu restoran dan cafe juga harus memberikan keunikan meliputi hal di atas agar menjadi daya saing yang dapat membedakan antara satu restoran dan cafe dengan lainnya yang akan memberikan nilai kepada pelanggan.

1. Perlu untuk ditingkatkannya perhatian dan pembinaan terhadap sektor pariwisata oleh pemerintah Kota dan Kabupaten Bandung mengingat bahwa sektor pariwisata merupakan sektor yang memiliki potensi yang cukup besar untuk dikembangkan. Hal ini terbukti dengan tingginya peran sektor pariwisata dalam meningkatkan pendapatan asli daerah. Tingginya peran sektor pariwisata dalam peningkatan pendapatan asli daerah ini tidak terlepas dari semakin maraknya usaha akomodasi seperti restoran dan rumah makan, café, dan hotel. Dengan semakin berkembangnya usaha pariwisata maka akan berpengaruh terhadap peningkatan pendapatan pajak yang akan berdampak pada kenaikan pendapatan asli daerah. Naiknya pendapatan asli daerah disertai dengan manajemen yang baik dari pemerintah Kota dan Kabupaten Bandung maka akan dapat meningkatkan perekonomian daerah.

\section{DAFTAR PUSTAKA}

A.B. Susanto, Agus W. Soehadi, Anny Nurbasari, Basu Swasastha, Budi Subroto, Faisal Afiff, Hadi Satyagraha, Lina Salim, Martani Hueseini, Teddy Pawitra 2004. Value Marketing, Paradigma Baru Pemasaran, Penerbit Quantum Bisnis \& Manajemen (PT. Mizan Publikasi): Jakarta Selatan.
\& Himawan Wijanarko. 2004. Power Branding: Membangun Merek Unggul dari Organisasi Pendukungnya. Mizan Media Utama: Bandung.

\& Himawan Wijanarko. 2004. Power Branding: Membangun Merek Unggul dan Organisasi Pendukungnya. Penerbit Quantum Bisnis \& Manajemen (PT Mizan Publikasi): Jakarta Selatan.

E Knapp: Duane. 2001. The Brand Bind Set. Alih Bahasa Drs. Sisnahudi, MBA. Yogyakarta: Andi

Hair, Joseph F, Jr., Anderson, Rolph. E., Tatham, Ronald L., Black, Wiliam C. 1998. Multivariate Data Analysis. Prentice Hall International : New Jersey.

Indonesia Tatler. 2005. Indonesia's Best Restaurants 2005. Illustrated Magazine Publishing co LTD 1811 Hong Kong Plaza. 1888 Connaught Road West Hong Kong.

Kandampully, Jay dan Dwu Suhartanto. 2000. Customer Loyalty in The Hotel Industry, The Role of Customer Satisfaction and Image. International Journal of Contemporary Hospitality Management. 12/6, p.112-120

Kaplanidou, Kiki \& Christine Vogt. 2003. Destination Branding: Concept and Measurement. Department of Park, Recreation and Tourism: Michican State University.

Lili Adi Wibowo, 2004, Pengaruh Experiential Marketing dan Emotional Value, terhadap Loyalitas Pelanggan Café dan Resto di Kawasan Cihideung Lembang Bandung. Jurnal Strategic Program Pendidikan Manajemen Bisnis Universitas Pendidikan Indonesia.

2004, Pengaruh Experiential Marketing terhadap Branded Customer Experience serta Dampaknya pada Loyalitas Pelanggan Café dan Resto di Kawasan Dago Pakar. Laporan Penelitian Individu dalam Program Due- Like Pendidikan Tata Niaga Universitas Pendidikan Indonesia. 
Smith, Shaun \& Wheeler, Joe. 2002. Managing The Customer Experience. Prentice hall.

Usmara, A 2003. Strategi Baru Manajemen Pemasaran. Amara Books: Jogjakarta.

Schmitt, Bernd, H. 1999. Experiential Marketing. The Free Press: New York.

Rogers, David L, \& Vrotsos, Karen. 2004. There's No Business That's Not Show Business: Marketing in a Experience Culture. Prentice Hall

\& Rogers. 2003. Customer Experience Management. John Wiley \& Sons INC: America.

2004. Creating and Managing Brand Experiences on The Internet. www.exstrategicmarketing.com.

\& Alex Simonson. 1997. Ringkasan Buku: Pemasaran Seni/Estetika-Strategi Manajemen terhadap Merek; Identitas dan Image. TCL Manajemen Konsultans. 